\title{
https://doi.org/10.46813/2021-136-030 \\ INFLUENCE OF RADIATION CONDITIONS ON CRACKING OF COMPOSITE SCINTILLATORS
}

\author{
A.V. Krech ${ }^{1, *}$, A.Yu. Boyarintsev ${ }^{1}$, N.Z. Galunov ${ }^{1,2}$, N.L. Karavaeva ${ }^{1}$, T.E. Gorbacheva ${ }^{1}$, \\ I.F. Khromiuk, L.G. Levchuk, ${ }^{3}$, V.F. Popov ${ }^{3}$ \\ ${ }^{1}$ Institute for Scintillation Materials NAS of Ukraine, Kharkiv, Ukraine; \\ ${ }^{2}$ V.N. Karazin Kharkiv National University, Kharkiv, Ukraine; \\ ${ }^{3}$ National Science Center "Kharkov Institute of Physics and Technology", Kharkiv, Ukraine \\ *E-mail: antonkrech@gmail.com
}

The article analyzes two main hypotheses describing the cracking of a composite scintillator in the irradiation zone. This is the "temperature" and "radiation-chemical" hypothesis of cracking. The analysis is based on experimental data that we obtained by irradiating scintillators and the results of model chemical experiments.

PACS: 29.40.Mc; 78.90.t

\section{INTRODUCTION}

Earlier [1 - 3] we investigated composite scintillators based on grains of organic or inorganic single crystals trying to find radiation-resistant materials. Under the action of the accumulated radiation dose $D$, the amplitude of the scintillation signal, before irradiation $I(0)$, decreases to $I(D)$ after irradiation. As in our previous works, we will follow the classical definition of a "radiation-resistant scintillator" formulated by Birks [4]. A scintillator is considered radiation-resistant up to the accumulated dose $D$ if the relative amplitude of the scintillation pulses $I(D) / I(0)$ is still greater than or equal to $1 / 2$.

Composite scintillators are single crystal scintillation grains inside a transparent base that is usually a gel composition. Composite scintillators have many advantages compared to classical scintillators. These advantages were described by us earlier in our previous works [1 - 3].

Earlier, we fabricated and studied composite scintillators based on the Sylgard-184 transparent dielectric gel composition containing inorganic grains GSO:Ce, GPS:Ce, $\mathrm{Al}_{2} \mathrm{O}_{3}: \mathrm{Ti}$, YSO:Ce, and YAG:Ce [1 - 3].

In our previous work [1] we studied the radiation resistance of the composite scintillators based on the grains of inorganic single crystals (GSO:Ce and GPS:Ce) in the polydimethylsiloxane. The composite scintillators based on GSO:Ce and GPS:Ce is radiationresistant at least to $D>200 \mathrm{Mrad}$ when dose rate is $0.2 \mathrm{Mrad} /$ hour and $D>250 \mathrm{Mrad}$ when dose rate is $1,500 \mathrm{Mrad} /$ hour. For higher doses, the samples of composite scintillators tend to crack. It results in a premature failure of the composite scintillator. In [2], we showed that composite scintillators containing $\mathrm{Al}_{2} \mathrm{O}_{3}$ :Ti grains began to crack at dose rates of 1.500 and $0.2 \mathrm{Mrad} /$ hour for $D$ values of 550 and $125 \mathrm{Mrad}$, respectively.

At first glance, a paradoxical situation arose. At a lower dose rate $(0.2 \mathrm{Mrad} /$ hour $)$, when the intensity of the radiation exposure was lower, the scintillators lost their properties at lower values of the accumulated dose $D$ than when irradiated with a high dose rate (1.500 Mrad/hour). It should be noted that at a low dose rate, it takes a longer time to increase the dose $D$ than at a high dose rate. In conducting these studies, we found the following unusual effect. As a result of prolonged exposure at a low dose rate $(0.2 \mathrm{Mrad} /$ hour $)$, in contrast to exposure at a high dose rate (1.500 Mrad/hour), a small amount of liquid appeared on the surface and around the composite scintillator. We measured the $\mathrm{pH}$ of this liquid with a universal indicator and found that the liquid has a $\mathrm{pH}$ of about unity. This means that the liquid obtained on the surface of the scintillator as a result of prolonged irradiation is a concentrated acid solution.

To explain the cracking of composite scintillators in [5], we considered the following working hypothesis. Cracking occurs in an atmosphere in which radiochemical reactions are possible. To analyze this hypothesis, we investigated several possible chemical reactions that could lead to cracking in the irradiated zone. We have performed the following experiments. Composite scintillators were placed in aqueous solutions (with $\mathrm{pH}=1$ ) of acids $\mathrm{H}_{2} \mathrm{SO}_{4}, \mathrm{HCl}, \mathrm{H}_{3} \mathrm{PO}_{4}$, and $\mathrm{HNO}_{3}$. The sulfuric acid dissolved the polymer base without cracking. After 72 hours, the degree of dissolution reached $90 \%$. We did not observe the effect of cracking in solutions of $\mathrm{HCl}$ and $\mathrm{H}_{3} \mathrm{PO}_{4}$ acids for 720 hours. In the process of destruction of samples in a concentrated solution of nitric acid, four stages were observed, which differ from each other, namely: 1) retention of elasticity (120 hours), 2) initiation of surface cracks during bending that does not lead to the destruction of the sample (240 hours), 3) manifestation of brittleness, namely, the sample is partially destroyed by the sample as a result of weak mechanical stress (480 hours), 4) spontaneous cracking of the sample ( 720 hours).

To exclude the presence of sulfuric acid in a liquid that can appear after irradiation, in [5] we also carried out a qualitative analysis of the presence of $\mathrm{SO}_{4}$ directly in the samples of this liquid. As a result, we showed that the acid $\mathrm{H}_{2} \mathrm{SO}_{4}$ does not form upon irradiation.

To confirm the presence of nitric acid in the liquid that appeared on the scintillator after irradiation, we performed a quantitative analysis of the content of $\mathrm{NO}_{3}$ ions in it. In chemical reactions with copper and $\mathrm{H}_{2} \mathrm{SO}_{4}$, we observed the evolution of brown gas $\left(\mathrm{NO}_{2}\right)$, which confirms the presence of nitric acid in the liquid (for more details, see [5]). 
In [6], we discussed the possible processes of radiation changes that occur during irradiation of composite scintillators containing grains of inorganic crystals and investigated the effect of these processes on the radiation resistance of composite systems. In addition, in [6], we proposed and studied possible processes of radiation-induced changes arising in composite scintillators under irradiation.

We have shown that crystalline scintillation materials contain defects that can act as quenching centres. Irradiation destroys and changes not only the base material but also these centres. As a result, during the lifetime of such modified centres, the luminescence intensity can increase due to the weakening of the quenching effect. In this case, the luminescence spectrum of the scintillator does not change its shape at different doses of $D$, since new luminescence centres are not formed Another possible process is associated with a change in the luminescence centres. This leads to a modification of the spectral characteristics of luminescence.

At the same time, these results do not answer the question: what is the nature of the cracking of composite scintillators at very high radiation doses? To answer this question in this article, we investigate the process of cracking of radiation-resistant composite scintillators after electron irradiation of the LU-10 linear accelerator. We investigate the cracking of composite scintillators during irradiation: in the atmosphere and vacuum.

\section{EXPERIMENTAL \\ 1.1. IRRADIATION OF THE SAMPLES}

As in previous works [1 - 3,6], electrons with an energy of $10 \mathrm{MeV}$ from the linear electron accelerator of the NSC "Kharkov Institute of Physics and Technology" irradiated scintillators at room temperature. The degree of inhomogeneity of the dose rate over the sample surface did not exceed 5\%. Plastic dosimeters Harwell Perpex 4034 and radiochromic film dosimeters FWT60-00 determined the dose rate (for more details, see [7]). The measurement error was $\pm 5 \%$. These dosimeters are limited to the maximum dose. Therefore, we used a set of identical dosimeters. A single dosimeter accumulated a relatively small dose interval. We determined the integral dose $D$ that the scintillator receives during irradiation by summing up the results of such successive measurements. We irradiated scintillators with two dose rates, namely $0.2 \pm 0.01 \mathrm{Mrad} /$ hour (mainly bremsstrahlung photons) and $1.500 \pm$ $5 \mathrm{Mrad} /$ hour (the electron beam directly scans the sample surface).

It is important to note that here and below all the dose values $D$ refers to the absorbed radiation dose in the water equivalent of the irradiated material.

The process of irradiation of composite scintillators takes place in the surrounding atmosphere. As noted above, we irradiated scintillators with either a low $(0.2 \pm 0.01 \mathrm{Mrad} / \mathrm{hour})$ or high $(1.500 \pm 5 \mathrm{Mrad} / \mathrm{hour})$ dose rate. In the first case, it was a flux, mainly of bremsstrahlung photons. In the latter case, the electron beam directly scanned the sample surface.

At a low dose rate, the accumulated dose $D$ reached $100 \mathrm{Mrad}$ in 500 hours, that is, in 20 days and 20 hours. At a high dose rate, the accumulated dose $D$ was
$500 \mathrm{Mrad}$ as a result of irradiation for 0.34 hours (i.e., 20 min.). At a high irradiation rate, the samples were on a conveyor belt that moved at a constant speed. The conveyor periodically moved the scintillators to the region of the direct electron beam. In one pass in front of the electron beam, which lasts $12 \mathrm{~s}$, the sample received a dose of about $5 \mathrm{Mrad}$. In this case, the sample was quickly heated. One pass of the conveyor with a return to the same point lasted about $40 \ldots 50 \mathrm{~min}$. During this pass, the sample was cooled. Repeated repetition of this process led to the accumulation of the required dose $D$. At the irradiation with the low dose rate, the samples were located in the experimental hall of the accelerator at a distance from the direct beam. The sample and the surrounding atmosphere were continuously irradiated with both electrons and bremsstrahlung radiation. In this case, the scintillators were always in the irradiation zone until they received the required dose $D[1-3,5,6]$.

\section{RESULTS AND DISCUSSION}

As noted above, composite scintillators based on grains of inorganic single crystals can begin to crack after the accumulation of significant radiation doses. In the article [5], we proposed and described the possible main reasons for the appearance of cracks. According to this article, composite scintillators can crack after irradiation for the following main reasons:

1) The effect of temperature on the sample in the irradiation zone;

2) The influence of aggressive atmospheric components (radiochemical processes).

The simultaneous action of these factors (synergistic effect) is also possible.

The first reason is related to the irradiation with the dose rate of $1.500 \mathrm{Mrad} /$ hour. In this case, a large amount of energy is absorbed, which leads to the significant heating of composite scintillators. This can lead to cracking of the composite scintillators at the interface between the grains and the gel composition.

The second case is typical for irradiation at the dose rate of $0.2 \mathrm{Mrad} /$ hour and is associated with the radiation effect of air ionization. Since irradiation occurs in the presence of air, chemically active compounds may form in the irradiation zone.

\subsection{THE EFFECTS OF CHEMICALLY AGGRESSIVE ATMOSPHERIC COMPONENTS}

As noted above, composite scintillators based on grains of inorganic single crystals can begin to crack after the accumulation of significant radiation doses. In the article [5], we proposed and described the possible main reasons for the appearance of cracks. According to this article, composite scintillators can crack after irradiation for the following main reasons:

1) The effect of temperature on the sample in the irradiation zone;

2) The influence of aggressive atmospheric components (radiochemical processes).

The simultaneous action of these factors (synergistic effect) is also possible.

The first reason is associated with exposure to a dose rate of $1.500 \mathrm{Mrad} /$ hour. In this case, a large amount of energy is absorbed for a short time, which leads to sig- 
nificant heating of the composite scintillators. This can lead to cracking of the composite scintillators at the interface between the grains and the gel composition.

The second case is typical for irradiation with a dose rate of $0.2 \mathrm{Mrad} / \mathrm{hour}$ and is associated with the radiation effect of ionization of the atmosphere. Since irradiation occurs in the presence of air, reactive compounds can form in the irradiated area.

After prolonged exposure at the low rate of irradiation, a certain liquid gradually forms on the surfaces and around the composite scintillators. $\mathrm{pH}$ analysis of this liquid confirmed that a strong acid solution is formed.

After prolonged exposure at a low irradiation rate, some liquid gradually forms on the surfaces and around the composite scintillators. The $\mathrm{pH}$ analysis of this liquid confirmed that it is a concentrated acidic solution.

We studied the effect of acids on composite scintillators. The following four acids we selected for this: $\mathrm{H}_{2} \mathrm{SO}_{4}, \mathrm{HCl}, \mathrm{H}_{3} \mathrm{PO}_{4}$, and $\mathrm{HNO}_{3}$ [5]. Samples of composite scintillators and gel compositions Sylgard-184 we placed in concentrated aqueous solutions of these acids.

Composite scintillators cracked only when placed in nitric acid. [8]

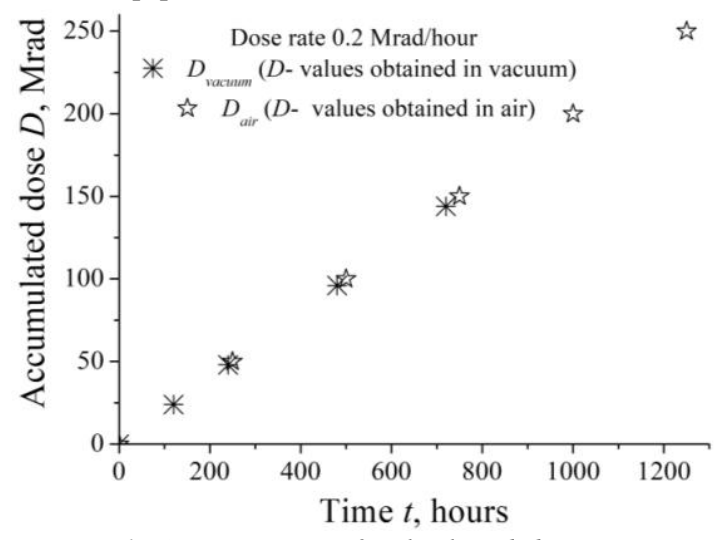

Fig. 1. Comparison of calculated doses $D_{\text {theor }}$ for composite scintillators in nitric acid and radiation doses $D_{\text {irrad, }}$ as functions of time $t$, capable of leading

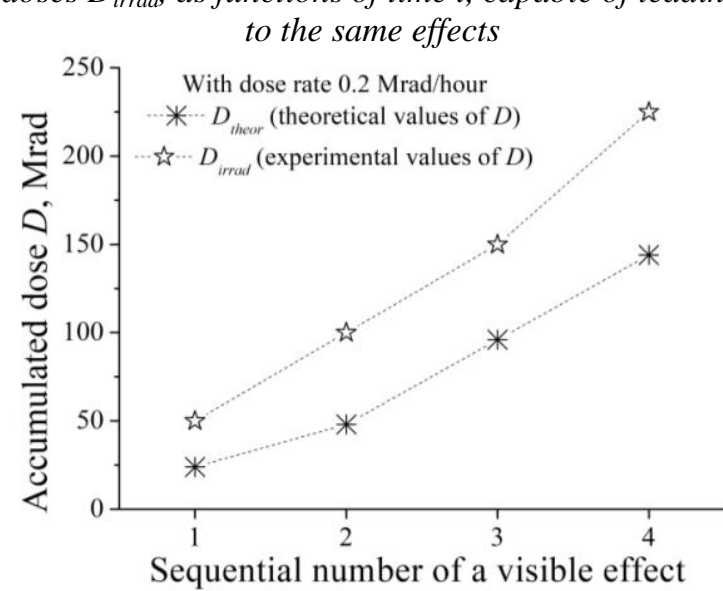

Fig. 2. Comparison of the calculated values of the $D_{\text {theor }}$ dose for composite scintillators immersed in nitric acid with the values of the $D_{\text {irrad }}$ dose, respectively, with the stages of visible effects: 1 -decrease in elasticity; 2 - the appearance of cracks during bending, which does not lead to the destruction of the sample; 3 - the manifestation of brittleness (the sample cracks under low mechanical stress); 4 -the sample becomes brittle (crumbles when touched, or spontaneously)
Fig. 1 shows the calculated values of the dose $D_{\text {theor }}$ that the composite scintillator can receive at a low irradiation rate $(0.2 \mathrm{Mrad} / \mathrm{hour})$ for the same time that it was in the acid. Fig. 1 demonstrates also the $D_{\text {irrad }}$ dose values (exposure at the same low radiation intensity).

The data in Figs. 1 and 2 correlate with each other. This means that our assumptions about the cause of crack formation in composite scintillators are correct. The nature of the destruction of the samples in acidic solutions indicates that, upon irradiation, both the vapour of nitric acid and the products of its radiolysis affect the scintillation samples. Note that always $D_{\text {theor }}<D_{\text {irrad }}$. This, as expected, indicates that the effect of the acid on the sample when it is completely immersed in acid is stronger than when the sample is in acid vapour or the products of its radiolysis.

To confirm the effect of the acid generated in the irradiation zone on the cracking of composite scintillators, the following experiment was carried out. We have manufactured two series of $\mathrm{Al}_{2} \mathrm{O}_{3}$ :Ti composite scintillators. We irradiated the first series of samples in air, and the second series was irradiated in a special box from which air was evacuated.

Acid formation upon exposure to a dose rate of $1.500 \mathrm{Mrad} /$ hour is unlikely due to the relatively short exposure time and heating to high temperatures. Therefore, to check the effect of acid on cracking during irradiation, a dose rate of $0.2 \mathrm{Mrad} /$ hour was chosen. Otherwise, the irradiation conditions were the same as in our previous works $[1,2,6]$. After every $25 \mathrm{Mrad}$ of irradiation, the composite scintillator samples we removed from the irradiation zone to measure their characteristics. Repeated irradiation cycles were carried out until cracking of the composite scintillators was observed.

Fig. 3 shows the observation results after every 25 Mrad of the accumulated dose.

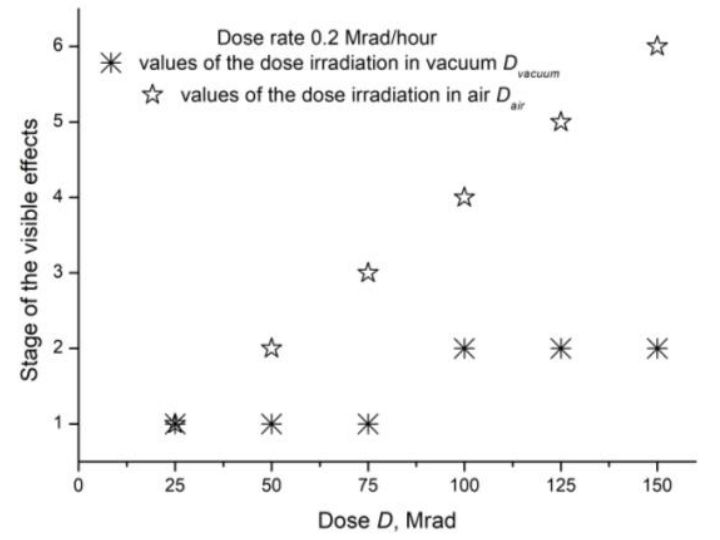

Fig. 3. Comparison of the visible effects after irradiation in air and vacuum in terms of D-values. Stage of visible effects: 1 - no visible effects; 2 - decrease in elasticity; 3 - cracks appear during bending, but the sample does not break; 4 - the manifestation of fragility (breaks down with a weak impact); 5 - the manifestation of fragility (disintegrates upon impact);

6 - samples spontaneously completely collapse

Fig. 3 shows the values of the irradiation dose $D$ at which the observations were carried out and the observed effect at this dose $D$. As can be seen from Fig. 3, the samples of composite scintillators irradiated in the 
presence of air decreased their elasticity with increasing irradiation dose $D$. This eventually led to their cracking. This is in good agreement with the results that we obtained in previous works. A different result is observed for samples irradiated in a vacuum. For them, at doses over $100 \mathrm{Mrad}$, only a slight decrease in elasticity was observed. Thus, this confirms that, when exposed to the products of radiochemical reactions in the atmosphere, it determines the cracking of composite scintillators at a low accumulated dose rate.

It should be noted that the relative light output of composite scintillators containing inorganic grains before their cracking was more than $L_{R e l}>0.5$ [8].

\subsection{THE TEMPERATURE EXPANSION OF A COMPOSITE SCINTILLATOR}

At a high radiation dose rate (in our case, $1.500 \mathrm{Mrad} / \mathrm{hour}$ ), the formation of a large amount of nitric acid is unlikely due to the short exposure time. In addition, due to the high temperature, condensation is also unlikely to form. How can a periodic increase in temperature lead to the cracking of composite scintillators?

When irradiated with a dose rate of $1.500 \mathrm{Mrad} / \mathrm{hour}$, a scintillator moving along a conveyor belt periodically enters the irradiation zone with a direct electron beam. During irradiation, a large amount of energy is absorbed, which leads to significant heating of the scintillators. Until the next arrival of the scintillator in the beam zone, it is cooled. Repetitive heating-cooling cycles can lead to cracking of composite scintillators at the interface between the grains and the gel composition. This may be due to the destruction of polymer bonds in the gel composition. Cracking can also occur due to different coefficients of thermal expansion of the scintillation grains and the composition of the gel.

More research is needed to separate the contribution of these factors. At a high dose rate, it is necessary to irradiate both the composite scintillator containing different amounts of grains and the pure composition of the gel composition. If the composite scintillator breaks first, this means that at high dose rates, the coefficient of thermal expansion is the main factor in the destruction of the sample. Otherwise, this would mean that the breakdown of polymer bonds in the gel composition is a more significant factor.

We are planning a series of such experiments soon.

\section{CONCLUSIONS}

When the values of the limiting doses given in $[1,2$, $5,6]$ are reached, namely $100 \ldots 200 \mathrm{Mrad}$ at a low dose rate, cracking of composite scintillators occurs. Howev- er, the relative luminous flux was more than $L_{R e l}>0.5$ before their destruction.

At the low rate of irradiation, the surrounding atmosphere in the irradiation zone has a significant effect on the cracking of composite scintillators due to radiochemical reactions occurring in it. Shown, that the main aggressive components, the action of which leads to cracking of the composite scintillator, are nitric acid and possible products of its radiolysis.

To avoid cracking of composite scintillators, they must be used in a vacuum or protected from corrosive substances formed in the air during irradiation. However, the aggressive environment in the irradiated zone does not directly affect the relative light output as long as the grains are protected by the gel composition.

\section{REFERENCES}

1. A.Yu. Boyarintsev, N.Z. Galunov, Ia.V. Gerasymov, et al. Radiation-resistant composite scintillators based on GSO and GPS grains // Nuclear Inst. and Methods in Physics Research, A. 2017, v. 841, p. 124-129.

2. N.Z. Galunov, T.E. Gorbacheva, B.V. Grinyov, et al. Radiation resistant composite scintillators based on $\mathrm{Al}_{2} \mathrm{O}_{3}$ :Ti grains and their properties after irradiation // Nuclear Inst. and Methods in Physics Research, A. 2017, v. 866, p. 104-110.

3. N.Z. Galunov, Ia.V. Gerasymov, T.E. Gorbacheva, et al. Composite scintillators based on single-crystal grains $\mathrm{Y}_{2} \mathrm{SiO}_{5}$ : $\mathrm{Ce}(\mathrm{YSO})$ and $\mathrm{Y}_{3} \mathrm{Al}_{5} \mathrm{O}_{12}$ : $\mathrm{Ce}$ (YAG) // Problems of Atomic Science and Technology. Series “Nuclear Physics Investigations”. 2017, № 3, p. 35-39.

4. J.B. Birks. The theory and practice of scintillation counting, London: "Pergamon Press Ltd". 1967, 662 p. (p. 205-211).

5. V.L. Cherginets, N.Z. Galunov, B.V. Grinyov, et al. Cracking of composite scintillators after significant doses of irradiation // Functional Materials. 2019, v 26, № 4, p. 690-694. https://doi.org/10.15407/fm26.04.690.

6. A.Yu. Boyarintsev, N.Z. Galunov, B.V. Grinyov, A.V. Krech. Development Features of RadiationResistant Materials for Composite Scintillators and Light Guides // Nuclear Inst. and Methods in Physics Research, A. 2019, v. 930, p. 180-184.

7. Available on http://www.harwell-dosimeters.co.uk/ harwell-red-4034; http://www.fwt.com/racm/fwt60ds.htm

8. A.Yu. Boyarintsev, N.Z. Galunov, T.E. Gorbacheva, et al. The Effect of Large Doses of Radiation on of Composite Radiation-Resistant Scintillators Cracking // Nuclear Inst. and Methods in Physics Research, A. 2020, v. 982, 164583, (p. 1-5).

Article received 27.09.2021

\section{ВЛИЯНИЕ РАДИАЦИОННЫХ УСЛОВИЙ НА РАСТРЕСКИВАНИЕ КОМПОЗИЦИОННЫХ СЦИНТИЛЛЯТОРОВ}

\section{А.В. Креч, А.Ю. Бояринцев, Н.З. Галунов, Н.Л. Караваева, Т.Е. Горбачева, И.Ф. Хромюк, Л.Г. Левчук, В.Ф. Попов}

Анализируются две основные гипотезы, описывающие растрескивание композиционного сцинтиллятора в зоне облучения. Это «температурные» и «радиационно-химические» возможные причины растрескивания. Анализ основан на экспериментальных данных, полученных нами при облучении сцинтилляторов, и результатах модельных химических экспериментов.

\section{ВПЛИВ РАДІАЦІЙНИХ УМОВ НА РОЗТРІСКУВАННЯ КОМПОЗИЦИЙНИХ СЦИНТИЛЯТОРІВ}

\section{А.В. Креч, А.Ю. Бояринцев, М.З. Галунов, Н.Л. Караваєва, Т.С. Горбачова, І.Ф. Хромюк, Л.Г. Левчук, В.П. Попов}

Аналізуються дві основні гіпотези, що описують розтріскування композиційних сцинтиляторів у зоні опромінення. Це «температурні» і «радіаційно-хімічні» можливі причини розтріскування. Аналіз заснований на експериментальних даних, отриманих нами при опроміненні сцинтиляторів, і результатах модельних хімічних експериментів. 